\title{
Improvement of urological-management abilities in individuals with tetraplegia by reconstructive hand surgery
}

\author{
Y Kiyono* $^{* 1}$, C Hashizume ${ }^{2}$, K Ohtsuka ${ }^{2}$ and Y Igawa ${ }^{3}$ \\ ${ }^{1}$ Department of Orthopaedic Surgery, Shinshu University School of Medicine, 3-1-1 Asahi, Matsumoto, Nagano, \\ 390-8621 Japan; ${ }^{2}$ Nagano Rehabilitation Center, 618-1 Yokochoh Shimokomazawa Nagano City, Nagano pref. \\ 381-8577 Japan; ${ }^{3}$ Department of Urology, Shinshu University School of Medicine, 3-1-1 Asahi, Matsumoto, Nagano, \\ 390-8621 Japan
}

\begin{abstract}
Objective: To evaluate whether reconstructive hand surgery could improve the ability of tetraplegic patients to perform clean intermittent self-catheterization (CIC).

Materials and methods: The subjects were patients with complete traumatic tetraplegia admitted to the Nagano Rehabilitation Center between 1977 and 1996. A total of 63 subjects were included in this study with an age range of 18-73 years (mean 38.2 years). Reconstructive hand surgery was performed on 44 hands (28 cases). Current urological conditions were assessed by interview or mail questionnaire.

Results: Fifty-one per cent (22/43) of the patients with C6 level of tetraplegia and $86 \%(12 /$ 14) of those with $\mathrm{C} 7$ or $\mathrm{C} 8$ neurological level of injury could perform $\mathrm{CIC}$ independently and only one subject needed assisted CIC.

Conclusion: CIC is the preferred option for people with tetraplegia. Reconstructive hand surgery is thus recommended to make urological management more independent for a selected group of people with tetraplegia.

Spinal Cord (2000) 38, 541-545
\end{abstract}

Keywords: tetraplegia; reconstructive hand surgery; urological management

\section{Introuduction}

Since Lapides et al introduced the technique of clean intermittent self-catheterization (CIC) in 1972, it has been used successfully by persons with spinal cord injury ${ }^{2-6}$ and the principle of low pressure voiding has been widely accepted. However, there are a limited number of reports ${ }^{7,8}$ which have examined in detail the ability of tetraplegic patients to manage CIC as a function of neurological level of injury (NLI). Unlike paraplegia, the residual hand function of people with tetraplegia very much depends on the spinal cord injury level, with differences being particularly marked at the $\mathrm{C} 6$ level.

Although several methods of urological management for tetraplegia have been introduced such as CIC, assisted catheterization, tapping voiding, indwelling urethral catheter, suprapubic cystostomy, ileal conduit formation etc., the optimal management of the neuropathic bladder in tetraplegic patients is multifactorial $^{9,10}$ and has not been critically examined. The method of bladder management, ${ }^{11}$ age, ${ }^{4}$ sex ${ }^{12,13}$ and individual management ability may affect the incidence of complications. Moreover, urological complications

*Correspondence: Y Kiyono, Department of Orthopedic Surgery, East Nagano National Hospital, 2-477 Uwano, Nagano City, Nagano 381-8567, Japan such as urinary tract infection, incontinence and renal deterioration can have a negative influence on patients' activities of daily living and prognosis.

The authors believe that optimal lower urinary tract management for people with tetraplegia should preserve renal function, while keeping the individual catheter-free and continent. This procedure usually consists of CIC combined with medical and/or surgical therapy to maintain a low bladder pressure during urine storage. However, many tetraplegic patients with inadequate hand function depend on family members or care attendants for assisted catheterization. ${ }^{7,13}$ At the Nagano Rehabilitation Center, reconstructive hand surgery has been performed since $1977^{14}$ in suitable tetraplegic patients to increase their independence in terms of ADL and urological management.

The aim of this study was to evaluate the effects of reconstructive hand surgery on urological management, especially CIC.

\section{Materials and methods}

Seventy patients with traumatic complete tetraplegia were reviewed, who had been admitted for inpatient rehabilitation to the Nagano Rehabilitation Center, Japan, between 1977 and 1996. Current urological 
conditions were assessed by interview or mail questionnaire. Two patients had died at the time of the follow-up and five could not be traced. A total of 63 patients, (60 men and three women) were thus available for this follow-up study.

Demographic information (age, sex, NLI, method of bladder management on admission, family and primary care giver, etc.) was obtained from medical records. NLI was classified according to the International Classification for Surgery of the Hand in Tetraplegia, Modified Giens 1984 (Table 1). ${ }^{15}$ NLI was determined by one and the same orthopaedic doctor at the time of discharge or at the time of reconstructive hand surgery, when the patients become neurologically stable. If the right and left NLI were different, the better side was recorded as the individual's level, as shown in Figure 1.
General characteristics of the sample

The average age at the time of injury was 33.7 (14-72) years, and $35.0(18-73)$ years at admission. The average period from hospital discharge until this follow-up study was $7.2(1.7-18.4)$ years.

Reconstructive surgery of the paralytic hand described by Zancolli ${ }^{16}$ was performed on 44 hands (28 cases). Surgical procedures in accordance with the international classification for surgery of the hand in tetraplegia were reconstruction of elbow extension (deltoid-to-triceps transfer) ${ }^{18}$ for Groups 1-3 (18 cases, 27 hands), pronation transfer of the biceps tendon by Zancolli ${ }^{17}$ for patients whose hand could not be pronated (six cases, eight hands), finger and thumb extension tenodeses for Groups 1-5, and intrinsic tenodeses, opponensplasty by tenodeses, and MP joint fusion for Groups $1-6 .{ }^{14}$

Table 1 International classification for surgery of the hand in tetraplegia, Edinburgh 1978 (modified - Giens, 1984) $^{15}$

\begin{tabular}{|c|c|c|}
\hline $\begin{array}{c}\text { Sensibility } \\
\text { or } \mathrm{Cu} \quad \text { Group }\end{array}$ & $\begin{array}{c}\text { Motor } \\
\text { Characteristics }\end{array}$ & $\begin{array}{l}\text { Description } \\
\text { Function }\end{array}$ \\
\hline 0 & No muscle below elbow suitable for transfer & Flexion and supination of the elbow \\
\hline 1 & BR & \\
\hline 2 & ECRL & Extension of the wrist (weak or strong) \\
\hline $3^{*}$ & ECRB & Extension of the wrist \\
\hline 4 & PT & Extension and pronation of the wrist \\
\hline 5 & FCR & Flexion of the wrist \\
\hline 6 & Finger extensors & Extrinsic extension of the fingers (partial or complete) \\
\hline 7 & Thumb extensor & Extrinsic extension of the thumb \\
\hline 8 & Partial digital flexors & Extrinsic flexion of the finger (weak) \\
\hline 9 & Lacks only intrinsics & Extrinsic flexion of the fingers \\
\hline $\mathrm{X}$ & Exceptions & \\
\hline
\end{tabular}

BR, brachioradialis; ECRL, extensor carpi radialis longus; ECRB, extensor carpi radialis brevis; PT, pronator teres; FCR, flexor carpi radialis. *It is not possible to determine strength of ECRL without surgical exposure

\begin{tabular}{|c|c|c|c|c|c|c|c|c|}
\hline \multirow{3}{*}{$\begin{array}{l}\text { Assisted catheterization } \\
\text { Indwelling urethral catheter }\end{array}$} & \multicolumn{4}{|c|}{ Reconstructive hand surgery } & - bilat. & \multirow[t]{2}{*}{ () uni. } & \multicolumn{2}{|c|}{$O$ none } \\
\hline & & & & $\bullet$ & & & & 63 \\
\hline & & & & ○ & & & & \\
\hline Suprapubic cystostomy & 0 & & 0 & 0 & & & & \\
\hline Ileal conduit & 0 & 0 & & 0 & (-) & (-) & & \\
\hline Tapping voiding & & & 0 & 80 & 80 & & 0 & \\
\hline C I C & & & (1) & 888 & 88 & 8 & 8 & 8 \\
\hline $\begin{array}{l}\text { International Classification } \\
\text { for Surgery of the Hand } \\
\text { in Tetraplegia }\end{array}$ & $\mathrm{C} 4 / 5$ & 0 & 1 & 2 & 5 & 7 & 8 & 9 \\
\hline
\end{tabular}

Figure 1 The relationship between NLI and methods of bladder management at follow up 


\section{Group 1}

Reconstruction of wrist dorsiflexion (brachioradialisto-radial wrist extensor transfer), ${ }^{19}$ tenodesis of finger flexors, and latero-lateral suture between radial wrist extensors and flexor pollicis longus (FPL).

\section{Group 2}

The same procedure as for Group 1, with the exception of brachioradialis-to-radial wrist extensor transfer.

\section{Groups 3, 4, 5}

Transfer of the brachioradialis to the FPL, and transfer of the extensor carpi radialis longus to the flexor digitorum profundus.

\section{Group 6}

Side-to-side suture of the extensor pollicis longus (EPL) and extensor digitorum communis, or tenodesis of the EPL. The remaining procedure was almost the same as that for Group 3.

After reconstruction, reevaluation and training for bladder management with adequate medication were carried out to improve urological management. The technique for CIC was taught by the occupational therapists and nurse. In order to permit easy accessibility to the genitals, adjustments were made to the individual's trousers that included Velcro closures and a looped zipper.

\section{Results}

Table 2 shows the changes in urological management in relation to the initial treatment. Tapping voiding (balanced voiding by reflex) was the most frequently used urinary management method $(38 \%)$ at the time of admission, followed by indwelling catheter $(21 \%)$, assisted catheterization (16\%), CIC (14\%), and suprapubic cystostomy $(5 \%)$. At the time of the follow-up, the main method of bladder management was CIC (56\%) and the second most common method was tapping voiding $(27 \%)$. Only one patient required assisted catheterization.

The relationship between NLI and urinary management method at follow-up is shown in Figure 1. Group 1/Group 1 (right/left hand) was the highest NLI found in those patients who could manage CIC independently after reconstructive hand surgery. In patients who did not have surgery, Group 2/Group 1 and Group 2/Group 2 were the highest NLIs observed among those who could manage CIC. Fifty-one per cent of C6 level patients (Groups 2-5) and $86 \%$ of C7 or C8 patients (Groups 6-9) could perform CIC independently. One female patient was discharged with an indwelling urethral catheter.

\section{Discussion}

The CIC procedure has become a generally accepted method of bladder management following spinal cord injury and it has now also been widely applied to tetraplegic patients. ${ }^{2,5,8}$ It has been the authors practice in the urological management of tetraplegic patients who can not be adequately treated with tapping voiding, to encourage independent CIC in order to enable them to achieve continence and remain catheter free. To improve their hand function and independence in ADL, reconstructive hand surgery has been undertaken where indicated since 1977. As a matter of course, the most appropriate method for each individual is assessed beforehand.

Asayama et $a l^{7}$ reported that $\mathrm{C} 6 \mathrm{~A} / \mathrm{C} 5 \mathrm{~B}$ (right/left hand) by Zancolli's classification (Table 3) ${ }^{16}$ was the highest NLI observed in patients who could manage

Table 2 The changes of urological management

\begin{tabular}{|c|c|c|c|c|c|}
\hline \multicolumn{3}{|c|}{ On admission } & \multicolumn{3}{|c|}{ At follow up } \\
\hline Management & & & Management & & \\
\hline \multirow[t]{4}{*}{ Tapping voiding } & 24 & (11) & Tapping voiding & 16 & $(7)$ \\
\hline & & & $\mathrm{CIC}$ & 6 & (3) \\
\hline & & & assisted CIC & 1 & (1) \\
\hline & & & Ileal conduit & 1 & $(0)$ \\
\hline \multirow[t]{4}{*}{ Indwelling urethral catheter } & 13 & $(6)$ & CIC & 8 & (4) \\
\hline & & & Suprapubic cystostomy & 3 & $(0)$ \\
\hline & & & Indwelling urethral catheter & 1 & (1) \\
\hline & & & Ileal conduit & 1 & (1) \\
\hline \multirow{2}{*}{ Assisted catheterisation } & 10 & $(5)$ & $\mathrm{CIC}$ & 8 & (4) \\
\hline & & & Ileal conduit & 2 & (1) \\
\hline \multirow[t]{2}{*}{$\mathrm{CIC}$} & 9 & $(1)$ & CIC & 8 & $(0)$ \\
\hline & & & Tapping voiding & 1 & (1) \\
\hline \multirow[t]{2}{*}{ Suprapubic cystostomy } & 3 & $(2)$ & Ileal conduit & 2 & (1) \\
\hline & & & CIC & 1 & (1) \\
\hline Unknown & 4 & (3) & $\mathrm{CIC}$ & 4 & (3) \\
\hline Total & 63 & (28) & & 63 & (28) \\
\hline
\end{tabular}

( ): Number of patients who had reconstructive hand surgery 
Table 3 Clinical classification of the quadriplegic hand by Zancolli ${ }^{16}$

\begin{tabular}{|c|c|c|c|c|c|}
\hline \multirow{2}{*}{$\begin{array}{l}\text { Lowest functioning } \\
\text { cord segment } \\
\mathrm{C} 5\end{array}$} & \multirow{2}{*}{$\begin{array}{c}\begin{array}{c}\text { Clinical } \\
\text { group }\end{array} \\
\text { I }\end{array}$} & \multirow{2}{*}{$\begin{array}{l}\text { Basic functioning muscles } \\
\text { Biceps }\end{array}$} & \multicolumn{3}{|c|}{ Subgroups } \\
\hline & & & A & & Without brachioradialis \\
\hline & & Brachialis & $\mathrm{B}$ & & With brachioradialis \\
\hline & & & A & & Weak wrist extension \\
\hline \multirow[t]{3}{*}{ C6 } & II & ECRL\&B & & 1 & Strong wrist extension \\
\hline & & & $\mathrm{B}$ & 2 & With PT \\
\hline & & & & 3 & With PT, FCR, and triceps \\
\hline \multirow[t]{2}{*}{$\mathrm{C} 7$} & III & EDC, EDQ, ECU & A & & Complete extension of ulnar fingers \\
\hline & & & $\mathrm{B}$ & & With EDP and weak EPL \\
\hline \multirow[t]{2}{*}{$\mathrm{C} 8$} & IV & FDP, EIP, EPL, FCU & A & & Complete flexion of ulnar fingers \\
\hline & & without intrinsic muscles & $\mathrm{B}$ & & Complete flexion of all fingers and weak FPL \\
\hline
\end{tabular}

ECRL\&B, extensor carpi radialis longus and brevis; PT, pronator teres; FCR, flexor carpi radialis; EDC, extensor digitorum communis; EDQ, extensor digiti quinti; ECU, extensor carpi ulnaris; EDP, extensor digiti proprius; EPL, extensor pollicis longus; FDP, flexor digitorum profundus; EIP, extensor indicis proprius; FCU, flexor carpi ulnaris; FPL, flexor pollicis longus

independent $\mathrm{CIC}$ by using a special device and C6B1 was the practical limit of NLI that preserved functional hands for independent CIC. In this study, the highest NLI found among those who could manage independent CIC was Group 1/Group 1 after reconstructive hand surgery, and without surgery, Group 2/Group 1 was the highest corresponding NLI after comprehensive rehabilitation.

Assisted catheterization by nurses or attendants is performed for many tetraplegic individuals, ${ }^{7,13}$ but assisted catheterization as a final goal of bladder management remains controversial, because this method requires considerable assistance from nursing staff or attendants. In our series, $51 \%$ of C6 level patients and $86 \%$ of $\mathrm{C} 7$ or $\mathrm{C} 8$ patients could perform CIC independently, while only one subject needed assisted CIC. Reconstructive hand surgery improved independence in all practical aspects of catheterization, including preparation of the catheter and bedpan, cleansing, insertion and withdrawal of the catheter, and the replacement of the instruments in the proper order. Since patients postoperatively no longer required assisted catheterization, the surgical intervention was considered successful both urologically and as a means of reducing nursing time. The independence also provided a great boost to the patients' morale and self-esteem.

A previous study of ours ${ }^{14}$ indicated that $\mathrm{C} 6 \mathrm{~B} 1 /$ $\mathrm{C} 6 \mathrm{~B} 2$ and $\mathrm{C} 6 \mathrm{~B} 3 / \mathrm{C} 7 \mathrm{~A}$ patients (Zancolli's classification; Table 3) could maintain ileal conduit formation independently after reconstructive hand surgery. This surgery is also recommended for tetraplegic people who need an ileal conduit for urological management.

Among the patients who initially used tapping voiding, many (16/24) preferred to continue with this method even though they had become independent in terms of CIC after reconstructive hand surgery, because they were familiar with the former procedure and felt somewhat repulsed by the idea of inserting a catheter into their urethra. Bakke et $a l^{9}$ reported that one-third of their SCI patients experienced CIC as aversive with significantly higher distress, especially in younger and female patients. They concluded more psychological support and closer follow-up should be provided for those individuals.

Tetraplegic patients who use tapping voiding need an adequate reflex bladder with a delicate balance between the detrusor and sphincter. However, this is not a static, but a dynamic phenomenon. ${ }^{4}$ Thus, regular follow-up studies are necessary; while intravesical voiding pressure should be monitored and reduced either with adequate anticholinergic drugs and/or transurethral sphincterotomy. If the maintenance of an acceptable intravesical pressure is difficult by tapping voiding, it should be replaced by CIC or other methods.

CIC has several advantages over tapping voiding. Residual urine is minimal, pharmacological control to keep dry is easier, and long-term prevention of renal deterioration is superior. ${ }^{2,6,8}$ Nevertheless, CIC has the potential risk of urinary tract infection. Technical problems and individual ability to prevent overdistension of the bladder may affect the incidence of complications. Moreover, maintenance of acceptable intravesical pressures and compliance with anticholinergic therapy, when indicated, are key elements of trouble-free CIC.

In conclusion, to preserve renal function and achieve urinary continence, CIC should be considered the method of choice for urinary management of patients with tetraplegia. After reconstructive hand surgery and comprehensive rehabilitation, the highest NLI of those who could manage independent CIC was Group 1/Group 1. Fifty-one per cent of C6 level patients could perform CIC independently. Reconstructive hand surgery is thus recommended to make urological management more independent for a selected group of patients with cervical spinal cord injury. 


\section{References}

1 Lapides J, Diokuno AC, Silver SJ, Lowe BS. Clean, intermittent self-catheterization in the treatment of urinary tract disease. $J$ Urol 1972; 107: $458-461$.

2 Chai T, Chung AK, Belville WD, Faerber GJ. Compliance and complications of clean intermittent catheterization in the spinal cord injured patient. Paraplegia 1995; 33: 161-163.

3 Hill VB, Davies WE. A swing to intermittent clean selfcatheterization as a preferred mode of management of the neuropathic bladder for the dextrous spinal cord patient. Paraplegia 1988; 26: $405-412$.

4 Madersbacher G, Oberwalder M. The elderly para- and tetraplegic: special aspects of the urological care. Paraplegia 1987; 25: 318-323.

5 Maynard FM, Glass J. Management of the neuropathic bladder by clean intermittent catheterization: 5 year outcomes. Paraplegia 1987; 25: $106-110$.

6 Perkash I, Giroux J. Clean intermittent catheterization in spinal cord injury patients: a followup study. J Urol 1993; 149: $1068-$ 1071.

7 Asayama $\mathrm{K}$ et al. The functional limitations of tetraplegic hands for intermittent clean self-catheterization. Paraplegia 1995; 33: $30-33$.

8 Sutton G, Shah S, Hill V. Clean intermittent self-catheterization for quadriplegic patients - a five year follow-up. Paraplegia 1991; 29: $542-549$.

9 Bakke A, Igrens LM, Malt UF. Clean intermittent catheterization-performing abilities, aversive experiences and distress. Paraplegia 1993; 31: 288-297.
10 Bejany DE, Lockhart JL, Rhamyn RK. Malignant vesical tumors following spinal cord injury. J Urol 1987; 138: 1390 - 1392.

11 Dewire DM, et al. A comparison of the urological complications associated with long-term management of quadriplegics with and without chronic indwelling urinary catheters [see comments]. $J$ Urol 1992; 147: 1069-1071. discussion 1071-1072.

12 Jackson AB, DeVivo M. Urological long-term follow-up in women with spinal cord injuries. Arch Phys Med Rehabil 1992; 73: $1029-1035$.

13 Timoney AG, Shaw PJ. Urological outcome in female patients with spinal cord: the effectiveness of intermittent catheterization. Paraplegia 1990; 28: 556-563.

14 Hashizume C, Fukui J. Improvement of upper limb function with respect to urination techniques in quadriplegia. Paraplegia 1994; 32: $354-357$.

15 McDowell CL, Moberg EA, House JH. The second international conference on surgical rehabilitation of the upper limb in tetraplegia (quadriplegia). J Hand Surg 1986; 11A: 604-608.

16 Zancolli E. Surgery for the quadriplegic hand with active, strong wrist extension preserved. A study of 97 cases. Clin Orthop 1975 112: $101-113$.

17 Zancolli E. Paralytic supination contracture of the forearm. $J$ Bone Joint Surg [Am] 1967; 49: 1275-1284.

18 Moberg E. Surgical treatment for absent single-hand grip and elbow extension in quadriplegia. Principles and preliminary experience. J Bone Joint Surg [Am] 1975; 57: 196-206.

19 Freehafer AA, Mast WA. Transfer of the brachioradialis to improve wrist extension in high spinal-cord injury. $J$ Bone Joint Surg [Am] 1967; 49: $648-652$. 